\title{
3 The Social Accounting Matrix (SAM) Framework
}

\subsection{Generalities}

The objective of a social accounts matrix is to provide to economic analysts a highly detailed record, consistent with the relations between different economic agents at a particular moment in time, usually the period of a year, presenting in one matrix the interaction between production, income, consumption, and investment. A SAM is the representation of the circular flow established in the economy by the flow of money, on the one hand, and the flow of goods and services, on the other. A SAM constructed on a country or regional basis remains mainly static. Below we present a prototype of a SAM.

SAMs are square matrices (columns reflect transposed rows) in the sense that all economic sectors or institutional agents (Firms, Households, Government, and 'Rest of Economy' sector) are both buyers and sellers. Columns represent buyers (expenditures) and rows represent sellers (receipts). SAMs were created to identify all monetary flows from sources to recipients, within a disaggregated national account. The SAM is read from column to row, so each entry in the matrix comes from its column heading, going to the row heading. Each column total equals each corresponding row total. As already said, this ensures accounting consistency in the context of general equilibrium.

The initiator of the SAM table is the Cambridge Growth Project in Cambridge, England, which developed the first SAM in 1962 (Brown \& Stone, 1962). This table was built as a matrix representation of the National Account. Finally, it was Graham (1985), the former associate of Stone in the 1960s who transferred SAM construction knowhow to the World Bank and became with E. Thorbecke, one of its leading proponents and developers on a worldwide scale.

One of the advantages of the SAM is it simplifies the design of the economy being modelled. As we will see in the next sections, a SAM forms the backbone of computable general equilibrium models or various types of empirical multiplier models.

The empirical importance of the SAM has influenced its form ${ }^{30}$, which clearly depicts spending patterns of an economy. SAMs are currently in widespread use in the world, and many statistical bureaus, particularly in OECD countries, create both a national account and this matrix counterpart.

As in the case of input-output matrices, a theoretical SAM should always balance, but empirically estimated SAMs never do so in the first collation. The source of these imbalances may be diverse, but the principal ones are the conversion of national accounting data into money flows and the introduction of non-SNA. Additionally,

30 IMPLAN and RIMS II data exploit these standardized data formats to implement much economic impact analysis.

2 Open Access. (C) 2017 Second Bwanakare, published by De Gruyter. (c) BY-NC-ND This work is licensed under the Creative Commons Attribution-NonCommercial-NoDerivatives 4.0 License. 
organizational problems in some countries can lead to conflicting sources of information, and the impossibility of balancing the constructed SAM creates a challenge. This problem was noted as early as 1984 by Mansur and Whalley (1984) and numerous techniques have been devised to 'adjust' SAMs, as "inconsistent data estimated with error." These techniques are similar to those discussed in the preceding chapter in the case of input-output tables, so they will not be discussed again here. As in the case of input-output matrices, when a SAM table is not balanced, this constitutes a case of the ill-behaved inverse problem. In fact, under this situation, besides a reduced number of accounts that we may claim to know with sufficient certainty, most of the accounts, about $n(n-1)$ of them, are known with uncertainty and the problem of indeterminacy usually arises. Robinson et al. (2001) first suggested a Shannon-Gibbs-Golan entropy based method for adjusting an unbalanced SAM of Mozambique's economy. Since then, as we will see later, a growing number publications applying this technique have been observed.

\subsection{Description of a Standard SAM}

The SAM table displays, in a systematic way, the circular flows inside macroeconomic accounts according to the bookkeeping principle (input equals output). Within that table, each account on the row stands for receipts by the sector at the left side of the same row. At the same time, these accounts constitute expenses by the sector situated on the top of the column. For instance, sector activities purchases "Intermediate Inputs" from the commodity sector. This means that this last sector receives a certain revenue from the activity sector.

Elements in the first column of sector activity (production sector) concern costs necessary to produce the global product at basic price. Thus, in this column are intermediary inputs (including imported goods) offered by different economic sectors, primary inputs (wages, operating surplus plus depreciation) and net indirect taxes (taxes on production minus subsidies from the government) on production. The second sector of commodities buys commodities from the activity sector on which direct taxes on consumption must be imposed - mainly value added taxes and import tariffs and duties. The commodity sector purchases goods from the rest of the world, i.e., imports, for internal consumption needs, complementary to commodities locally produced. Primary factors pay incomes from sold services to their owners (households, enterprises) in the activity sector. Primary factors disburse social security premiums to social institutions in exchange for insurance.

Households, thanks to income received from factors of production or public transfers, purchase goods for private consumption, pay direct taxes to the government, as well as taxes on wealth and other revenues and different non-tax disbursements in favour of local government. Households save income, not disbursed, for current needs and charges, and private banks receive these amounts for savings. 
Enterprises disburse a part of their income in favour of their owners, i.e., households. Enterprises pay corporate taxes and the public sector factor in favour of government.

Next, social security institutions, which have received social security premiums from households, disburse social security expenditures in relation with insurance contract execution.

Government institutions disburse received income (mainly from taxes and other government charges) to consume commodities, to make transfers to households, and grant subsidies to enterprises, pay interest on domestic and foreign debts, and save the remaining income.

Domestic banks, like any other private enterprise, distribute net profits to households, pay taxes to the government, and disburse saved money for investment; they may also lend (national bank) money to the government to finance the difference between public investment and public savings. Finally, domestic banks pay interest to foreign banks.

Capital Account represents durable materials purchased from commodities for private or public investments.

Rest of the world (ROW), that is, foreign countries and institutions, import (our exports) goods and services locally produced, and pay remittances to national production factors. It pays private transfers of our enterprises residing in foreign countries. This account appears as a balance, taking into account transfers made by foreign enterprises residing inside our country. Rest of the world finances domestic banks, too. This happens, in particular, when branches of international banks are located inside the national territory.

In spite of the sectorial equilibrium between demand and supply predicted by theory-that is, in terms of the social accounting matrix, balancing respective rows and columns-the system of data collecting and organization of national accounting are far from perfect. As a consequence, we get a social accounting matrix which is unbalanced, at least for a few of the sectorial accounts.

This is generally the case for institution accounts like households, enterprise, government, and non-profit organizations. That is, contrary to the above explained conservation law, general equilibrium is not attained. For instance, total revenue of enterprises is lower than their total expenditures, and the situation is reversed in the case of the government. The principles of market clearance and of zero-profit may not be satisfied in the case of the enterprise sector. The principle of balanced budget account is not satisfied in the case of government. In practice, the case of no balanced accounts constitutes the rule rather than the exception. To balance respective rows and columns, economists may implement arbitrary economic hypotheses such as those related to closure rules ${ }^{31}$ or use different quantitative techniques already dis-

31 The essential problem is that the classic CGE model, in which all markets clear, yields a full-em- 
cussed above in the case of balancing input-output tables. Some of these techniques are more or less reliable. This is the case for the least squares or the linear programming methods, but their accuracy remains poor, as already noted. The bi-proportional RAS method (Golan et al., 1996) is relatively powerful. However, it is a not appropriate for the imposition of restrictions with random errors in the model.

Fortunately, recent techniques of cross-entropy econometrics display interesting estimation properties and seem to be adapted to such ratio problems. The next section presents the cross-entropy technique which will be applied to balance a social accounting matrix of Gabon (see output details in Bwanakare (2013)) or to present further applications of the procedure by balancing the ecological SAM of Poland (see Tables 23 and 24). As is well known, disaggregating a SAM requires a lot of, often non-reconcilable, information which worsens its equilibrium. This is particularly true in developing countries. The case of disaggregating labour or household accounts without reliable information to split them up should be emphasised.

ployment equilibrium and market-clearing prices, while short-run macro models typically involve wage and price rigidities, partial adjustment mechanisms, and equilibrium without market clearing, including unemployment. The two paradigms embody very different notions of equilibrium. http:// www.ifpri.org/events/seminars/2003/20031014/robinson_thorbecke_EPIAM.pdf 